\title{
Interactive comment on "Modeling Trans-Pacific Transport using Hemispheric CMAQ during April 2010: Part 1. Model Evaluation and Air Mass Characterization for the Estimation of Stratospheric Intrusion on Tropospheric Ozone" by Syuichi Itahashi et al.
}

\section{Heini Wernli}

heini.wernli@env.ethz.ch

Received and published: 19 June 2019

I share the concerns raised by the 2 nd reviewer about model resolution and the description of the setup of the stratospheric tracer O3PV. In addition, I would like to comment on the issue of using PV to identify "air of stratospheric origin". According to Fig. 10, an air mass is classified as a strong/moderate/weak stratospheric intrusion if PV is larger than $3 / 2 / 1$ pvu. Here it is not fully clear what "strong" and "moderate" mean: if air with 
$P V>2$ pvu is stratospheric then why calling PV $>3$ pvu "strong intrusion"? It has higher $\mathrm{PV}$ but this paper is about ozone. This measure of "strength" does not necessarily reflect the influence on ozone. Things become more problematic in the text where it reads: "At least, a PV value of 1.0 PVU and corresponding $\mathrm{RH}$ (from Table 5) are required to judge stratospheric origin." Note that "stratospheric origin" is not the same as a "stratospheric intrusion". An originally stratospheric air parcel that experiences STT, first has high PV (> 2pvu) and, most likely, high O3. It then loses PV due to some diabatic process (turbulence, radiation, convection) and enters the troposphere (what we call STT). Ozone values might still be high. Entering further into the lower troposphere many things can happen: diabatic processes can further reduce PV (to very low values of less than $1 \mathrm{pvu}$ ), the air parcel may become moister (due to turbulent mixing) and its $\mathrm{O} 3$ value might change due to mixing and photochemistry. At this stage, which is essential for the objective of this study, there is not necessarily a high correlation between PV and O3: PV might be very low but $\mathrm{O} 3$ still elevated due to its stratospheric origin. Importantly: this air mass is still of "stratospheric origin"! Therefore, a threshold of $1 \mathrm{pvu}$, as applied in this study, can be very misleading to identify air masses of stratospheric origin. In other words, just because PV goes below 1 pvu, the air parcel composition does not necessarily lose its stratospheric characteristics. I would find it much more meaningful to use a simulated passive stratospheric tracer to identify air of stratospheric origin and then to quantify the effects on mixing and photochemistry on ozone in these air parcels. The following papers about STT might also be helpful to the authors for further developing their methodology and for validating their results.

Lefohn, A. S., H. Wernli, D. Shadwick, S. J. Oltmans, and M. Shapiro, 2012. Quantifying the importance of stratospheric-tropospheric transport on surface ozone concentrations at high- and low-elevation monitoring sites in the United States. Atmos. Environ., 62, 646-656.

Škerlak, B., M. Sprenger, and H. Wernli, 2014. A global climatology of stratospheretroposphere exchange using the ERA-Interim dataset from 1979 to 2011. Atmos. 
Chem. Phys., 14, 913-937.

Škerlak, B., S. Pfahl, M. Sprenger, and H. Wernli, 2019. A numerical process study on the rapid transport of stratospheric air down to the surface over western North America and the Tibetan Plateau. Atmos. Chem. Phys., 19, 6535-6549.

Interactive comment on Atmos. Chem. Phys. Discuss., https://doi.org/10.5194/acp-2019-203,

Interactive

comment 2019. 